\title{
UK 'must pay up' for costs of hospital merger
}

London. The British government has been urged to make an "unequivocal commitment" to provide at least $£ 100$ million to secure the future of research at the Hammersmith Hospital in London - one of the country's leading clinical research institutions - if, as many expect, it decides to move the hospital facilities to a site several miles away already occupied by the Charing Cross Hospital

The proposal is made implicitly in a report prepared for the Department of Health by Sir David Phillips, the former chairman of the Advisory Board for the Research Councils, and Sir Rex Richards, a former vice-chancellor of the University of Oxford, which was presented to Mrs Virginia Bottomley, the health secretary, last week

The report says that, in order to curtail uncertainty over the fate of the various institutions sharing the Hammersmith Hospital site, a decision on whether the hospital is to be moved should be taken "urgently and irrevocably". These institutions include in particular both the Royal Postgraduate Medical School (RPMS) and the Medical Research Council's (MRC's) Clinical Sciences Centre, due to be opened in April.

But it also concludes that the money needed to ensure the continued quality of Hammersmith's research must both be protected and "seen to be protected" until the completion of any move, which is likely to take a minimum of five years.

"We appreciate that this would be difficult, given the financial framework within which the government operates," say the two authors of the report. "But we believe it to be essential that some means be found to assure researchers that intentions would be implemented, and that funding would not be a cause of delay or change."

The report comes at a time when health department officials are completing final discussions on a decision that will have a major

\section{Hot-line will answer scientific queries}

London. An information line allowing the British public to have their scientific questions answered over the telephone is to be opened in London next week by William Waldegrave, the minister for science, as part of the government-backed Science Week.

Known as Science Line, the information service has already been tested on a limited scale following the broadcast of various television programmes on scientific topics. More than 800 calls, for example, were received last summer following a programme on dinosaurs, and there was a similar response to programmes on memory impact on the future of London as one of the world's major centres of biomedical research.

The merger between the two hospitals has been proposed as a response to falling demand for beds at the two hospitals, itself the result of both demographic shifts and government policies that are discouraging physicians elsewhere in Britain from sending their patients to London for treatment.

\section{IMAGE UNAVAILABLE FOR COPYRIGHT REASONS}

No decision has been taken on which of the two will close. But the Charing Cross Hospital is the more popular of the two with both patients and general practitioners, because it is considerably more accessible than the Hammersmith. It is also situated in a marginal parliamentary constituency currently held by the Conservatives.

Medical researchers at the Hammersmith Hospital, however, are warning that, if their institution is to be the one that has to move, the future of many research teams with an international reputation could be threatened.

Almost a thousand top biomedical researchers have signed a letter to Bottomley pointing out that last year, for example, two Hammersmith research departments achieved top scores in a research assessment exercise carried out by the Higher Education Funding Council for England. They also emphasize that the hospital has been selected by the MRC as one of the main

\section{and gene therapy.}

The expansion of the service is being made possible primarily by a grant from the Wellcome Trust, with additional support from the Royal Society and Channel 4 television, as well as the Office of Science and Technology.

Other activities included in Science Week range from laboratory open days in many universities to an experiment being organized by the British Broadcasting Corporation to test the hypothesis that people lie more convincingly on video than either on radio or in print. focal points of a new initiative to boost long-term clinical research in areas such as human genetics and immunology.

Already, however, uncertainty over the future of the Hammersmith is causing difficulties. For example, those responsible for recruiting research teams for the new Clinical Sciences Centre, being funded jointly by the MRC and the Wellcome Trust, are finding some positions difficult to fill (Nature 365, 477; 1993).

Many existing staff are considering whether to take up offers of jobs elsewhere. "The problem is that, faced with the prospects of a major upheaval five years down the road, people will just leave," says Karol Sikora, professor of oncology.

Phillips and Richards were not asked to judge whether the merger was a good idea, or even which of the two sites should be the one occupied by the new, single hospital, but to comment on the feasibility of a merger and the steps needed to minimize the impact on research.

The report endorses the long-term goal of grouping institutions such as the RPMS into a multi-campus College of Medicine, bringing together a number of West London biomedical teaching and research institutions under a single administration, with undergraduate teaching focused on Imperial College. It says that, as a first step towards this goal, the government needs to commit itself to funding a new pre-clinical building at Imperial College.

Officials at Hammersmith, still keen to avoid being moved to the Charing Cross Hospital, are emphasizing the endorsement the report provides of the high quality of research at the hospital. "The report points out that to move the Hammersmith to Charing Cross will be expensive and risky," Sir Colin Dollery, the dean of RPMS, said last week. "There is no previous experience of moving a hospital of this complexity, and it would be both unwise and unnecessary."

No firm figures are quoted by Richards and Phillips in their report. But one calculation is that at least $£ 100$ million, and probably considerably more, would be needed to reproduce on the Charing Cross site all the research facilities currently in operation at Hammersmith.

So far, the government has given no indication that it will be prepared to guarantee to provide the necessary funds. But as Sir Walter Bodmer, director-general of the Imperial Cancer Research Fund Laboratories, puts it: "If the decision is made for the Charing Cross site without securing the money needed to make the move properly, the Hammersmith will be destroyed, and anyone who makes that decision will rue the day they did so."

David Dickson 